\title{
LAS «TERCERAS VÍAS» DE LA SOCIALDEMOCRACIA DURANTE LOS AÑOS 90
}

\author{
ISRAEL SANMARTÍN ${ }^{1}$ \\ Universidad de Santiago de Compostela
}

\begin{abstract}
Resumen
Se analizan las diferentes opciones que adoptó la socialdemocracia durante los años 90 . En un momento de cambios e incertidumbres con la pérdida de uno de los pivotes ideológicos en la izquierda tras el derrumbre del llamado «socialismo real», se intensificó el diálogo entre las diferentes izquierdas de ambos lados del atlántico. Uno de los frutos de esa confluencia fue la «Tercera Vía» de Guiddens/Blair, quienes quisieron monopolizar las nuevas vías por las que deviera discurrir la socialdemocracia en un futuro. El trabajo muestra la existencia de otras «Terceras vías» tanto en EE.UU como en Europa y esboza que la llegada de las ideas alterglobalizadoras fueron el verdadero revulsivo para la izquierda, que por fin supo asimiliar críticamente todo lo sucedido a finales de los 80 y supo plantear nuevas alternativas, que situaron en el mapa a una nueva socialdemocracia mucho más a la izquierda que lo que quisieran ver esas «Terceras Vías».
\end{abstract}

\section{Palabras Clave}

Tercera Vía, progresista, socialdemocracia, antiglobalización, liberal, Guiddens, Clinton, Blair, Schröeder.

\begin{abstract}
The different options that the social democracy took on during the nineties are analyzed in this article. In a moment of changes and uncertainties with the loss of one of the ideological pivots in the left after the collapse of the called «real socialism», the dialogue between the different lefts of are intensified. One of the fruits of that confluence was the «Third way» of Guiddens/Blair, who wanted to monopolize the new ways for which the socialdemocracy had to go in a future. The work shows the existence of other "Third ways» in EE.UU and in Europe and sketches that the arrival of the antiglobalization ideas were the revulsive for the left, that it knew how to assimilate critically everything the happened at the end of the eighties and knew how to consider new alternatives, which situated in the map to a new socialdemocracy much more to the left than what wanted to see those «Third ways».
\end{abstract}

\section{Key Words}

Third ways, socialdemocray, antiglobalization, liberal, Guiddens, Clinton, Blair, Schröeder.

${ }^{1}$ Dirección electrónica: isanmartin@cesga.es 
$\mathrm{E}$ 1 gran cambio que supuso la caída del Muro de Berlín y las llamadas «revoluciones liberales» en los países del Este y la antigua URSS, y el posterior retorno de los ex-comunistas en muchos de estos países (bajo siglas socialdemócratas) ${ }^{2}$, estuvieron acompañadas por un cambio de contexto en el mundo anglosajón y europeo durante los años 90. Ese cambio se produjo en Estados Unidos a partir del año 1992 con la llegada de Bill Clinton a la presidencia. En Europa comenzó lentamente y cristalizó en 1998 con la victoria del Partido Socialdemócrata Alemán (SPD), y su líder Gerhard Schröeder, así como la confirmación del ex-comunista Massimo D'Alema como presidente italiano. En ese momento todos los gobiernos de la Unión Europea eran socialistas, excepto Irlanda y España. Asistíamos a un «momento progresista» al menos en apariencia. Aunque se trataba de partidos socialistas, no todos tenían las mismas ideas ni los mismos objetivos. Muchas de estos partidos continuaron con los presupuestos ultraliberales de la New Right de Reagan y Thatcher, pero abordando los problemas desde otras sensibilidades y posturas. Las ideas neoliberales han mostrado una gran robustez hasta que durante los 90 se llegó a comprender el largo alcance que habían alcanzado (aumento de desigualdad, pobreza, etc.). Esta comprensión fue aupada, en gran parte, por este contexto progresista, la revuelta de Chiapas y manifestaciones en 1995 en Francia, en un primer momento; y las manifestaciones de los grupos antiglobalización después, que han hecho surgir una nueva izquierda alternativa y han dejado en evidencia muchas de las «Terceras Vías» planteadas durante esos años.

El dominio republicano en Estados Unidos, del liberalismo en Gran Bretaña y en el continente habían dejado una profunda impronta política, económica y social. Ninguno de los nuevos partidos socialistas europeos coincidían con los esquemas de la vieja izquierda. Un cierto espíritu «práctico» y renovador antecedía a cualquier principio ${ }^{3}$. El escenario había cambiado. La batalla no era entre capitalismo y socialismo real, sino entre liberales y socialdemócratas dentro de la economía de libre mercado 4 . La larga hegemonía iniciada por Margaret Thatcher y Ronald

\footnotetext{
${ }^{2}$ Evidentemente no es lo mismo la aplicación de políticas socialdemócratas por políticos excomunistas que por políticos social-liberales o socialdemócratas clásicos. El punto de partida es diferente.

${ }^{3}$ Se habían abandonado los principios de la «vieja izquierda», como la lucha de clases social y económica por parte de los trabajadores y los menos favorecidos, y la batalla por mayores libertades políticas y la afirmación y defensa de los derechos humanos. Los socialistas han pasado, en palabras de William Pfaff, a una política de «resolución de los problemas». PFAFF, William, «La nueva izquierda europea: el ejemplo francés», Política Exterior, n 67 , Enero/Febrero 1999, pp. 59-68.

${ }^{4}$ Ver ESTEFANÍA, Joaquín, Contra el pensamiento único, Taurus, Madrid, 1997.
} 
Reagan transformó casi completamente la «vieja izquierda» liberal, la del Partido Laborista británico (llamado ahora Nuevo Laborismo) y la del Partido Demócrata estadounidense. Ambos partidos iniciaron, arrastrando a parte de la izquierda europea, un viaje hacia el centro que les llevó a aceptar premisas de la derecha, como la defensa del «menos gobierno» ${ }^{5}$ y la campaña contra el Estado de bienestar. Ambos optaron por acercarse a políticas neoliberales pero mantuvieron un envoltorio progresista, pese a que continuaron las privatizaciones, liberalizaciones, desregulaciones, reducción de programas sociales, aumento de violencia, etc. Analizaremos en este trabajo el caso estadounidense y el europeo (con sus variantes y críticas), para, por último, establecer una conclusión.

\section{EL CASO ESTADOUNIDENSE}

William Jefferson «Bill» Clinton, antiguo gobernador de Arkansas, ganó a George Bush en las elecciones de 1992 interrumpiendo doce años consecutivos de presidencia republicana, encarnando, entre otras cosas, la esperanza de retomar una ambiciosa política social ${ }^{6}$. Pese a ello, Clinton durante sus dos mandatos ha tenido que convivir con un Congreso con mayoría republicana ${ }^{7}$. Ha promovido el libre comercio internacional, la presentación de presupuestos equilibrados, y ha suprimido los subsidios públicos a los parados que demuestran ser capaces de trabajar. El resultado de su gestión y de la coyuntura económica durante su mandato fue que Estados Unidos se encontró en un periodo de prosperidad económica de una duración sin precedentes, con un crecimiento y nivel de empleo en continua subida. Recordando a Alvin Toffler, se pasó del eslogan «The economy, stupid» ${ }^{8}$ al

\footnotetext{
${ }^{5}$ En palabras de SAID, Edward S., «Problemas del neoliberalismo», El País, 3 octubre de 2000.

${ }^{6}$ Clinton prometió «acabar con el Bienestar tal como lo conocemos» pero no acometió esas reformas hasta que el Partido Republicano presentó en enero de 1995 unas reformas más radicales que las que Clinton había planteado, dando mayor autonomía a los estados para que formulen sus propias políticas. El caso de New Jersey es estudiado por Ted Goertzei de la Universidad de Rutgers. GOERTZEL, Ted, «La psicología política de la reforma de bienestar en los Estados Unidos. El caso de New Jersey», Psicología Política, ${ }^{\circ}$ 10, 1995, pp. 7-24.

${ }^{7}$ Clinton tuvo que plegar mucho de su programa a partir de 1994 cuando los republicanos lograron por primera vez la mayoría en el Senado y en la cámara de representantes desde 1952. Los republicanos, encabezados por Newt Gengrich, defendían el equilibrio presupuestario a cambio de cortes drásticos en los gastos sociales; menos Estado y menos impuestos. Ver FURET, François, «Los Estados Unidos de Clinton», Vuelta, n 246, Mayo de 1997, pp. 8-12.

${ }^{8}$ Contestación famosa que ha servido de comentario y título de muchos artículos desde ese momento. Fue la respuesta a un publicitario que preguntó sobre la prioridad en la campaña de
} 
«No se permite fumar»; de una economía dominada por los políticos a un nuevo estilo de vida centrado en la reducción de la burocracia y del papel de los Gobiernos, así como el debilitamiento de los partidos políticos en beneficio de las ONG's?.

La situación se había deteriorado durante 1991 y 92 . El norteamericano medio percibía el último tramo de dominio republicano (el mandato de Bush) con una sensación de descenso de poder adquisitivo debido, entre otras razones, a la pérdida de competitividad de la industria americana. El gobierno republicano logró insuflar a las ciudades un envoltorio de ansiedad y miedo ante la marginación y criminalidad, y agrietar considerablemente la distancia entre las clases cultas urbanas (más sofisticadas, más permisivas e imaginativas) frente a la tradicional y demográficamente dominante clase media de localidades medianas y pequeñas ${ }^{10}$.

La clase media evolucionaba contra Bush por su escasa atención a la política interior y su dedicación a los asuntos mundiales (un serio aviso fueron los sucesos de Los Ángeles con cuarenta muertos en las calles y barrios enteros incendiados por los insurrectos). Las minorías empezaron a revolverse con movimientos protesta en Washington, Boston, New York, atacándose entre sí (los suburbios negros, los asiáticos del Oeste, las bolsas de pobreza de los Grandes Lagos, etc). Todo este escenario de descontento se recargaba más si se fondeaba en las calas del déficit presupuestario ${ }^{11}$ y comercial.

Para salir al paso de esta caótica situación, Clinton propuso la idea del «contrato generacional $\rangle^{12}$, que insistía en la conservadora idea de que existe un contrato entre generaciones que debe de ser respetado y según el cual las generaciones actuales deben fidelidad a las que ya pasaron, pero han de ser fieles a las que han de venir; y no sólo a los hijos, sino a los tataranietos. Como buen «nuevo demócrata», se comprometió con los valores tradicionales de la familia y el trabajo ${ }^{13}$.

Clinton en 1992. Ver, VALCÁRCEL, Darío, «La América de Clinton: peligros del aislamiento, riesgos del liderazgo», Política Exterior, Vol. VII, n 31 , p. 8.

${ }^{9}$ Ver TOFFLER, Alvin, La Tercera Ola, Plaza \& Janés, Barcelona, 1990.

${ }^{10}$ Ver VALCÁRCEL, Darío, «La América de Clinton: peligros del aislamiento, riesgos del liderazgo», Politica Exterior, Vol. VII, nº 31, p. 8.

${ }_{11} 295.000$ millones de dólares en el año 92 (muchos de ellos para financiar la carrera armamentística), aunque el último año de Bush dejaba la buena noticia de signos visibles de recuperación económica gracias a la estabilidad de precios, lucha contra la inflación y bajas tasas de interés. Ver VALCÁRCEL, Darío, «La América de Clinton: peligros del aislamiento, riesgos del liderazgo», p. 9.

${ }^{12}$ Ver VALCÁRCEL, Darío, «La América de Clinton: peligros del aislamiento, riesgos del liderazgo», p. 8.

${ }^{13}$ Ver GOERTZEL, Ted, «La psicología política de la reforma de bienestar en los Estados Unidos. El caso de New Jersey», Psicología Política, n 10, 1995, pp 103-105. 
Clinton ${ }^{14}$ proponía un saneamiento de la balanza comercial unido a un gran esfuerzo en la formación profesional y en investigación científica y desarrollo (I+D), además de la creación de empleo y recorte presupuestario ${ }^{15}$. Pero había otros obstáculos para la recuperación, como el problema educativo, el alza de la economía especulativa frente al esfuerzo productivo, la persecución del beneficio empresarial a corto plazo, la búsqueda del dividendo frente a la inversión y la austeridad, el auge de los bonos basura, los brotes de información privilegiada y tráfico de influencias, o la cultura del consumo frente al ahorro ${ }^{16}$.

Los dos primeros años de Clinton fueron decepcionantes. Las promesas de profunda transformación del Estado no se llevaron a cabo ${ }^{17}$. Empezó a ganarse fama de hombre de poco carácter y caprichoso. La idas y venidas en los nombramientos y la ineficacia en las decisiones en asuntos de política externa e interna, se sumaron a los escándalos y devaneos de juventud aireados por medios conservadores ${ }^{18}$. En 1994 Clinton dio un giro a su política tras la victoria republicana en el Congreso ${ }^{19}$.

\footnotetext{
${ }^{14}$ Su principal asesor y estratega ha sido durante todos los años de su mandato Sidney Blumenthal, quien ha sido el creador de una corriente surgida en Estados Unidos que se denominó New Democrats y que sacó de su estancamiento a los liberales en Estados Unidos y posteriormente ayudó a la formación de la "Tercera Vía», organizando congresos y reuniones entre sus máximos dirigentes. Ver EL Mundo, 14 de enero de 2001, pp. 7-9.

${ }^{15}$ Aunque desde medios republicanos se dudaba desde un principio de su programa de equilibrio presupuestario sin reducción de tasas. Un ejemplo se puede encontrar en William A. Niskanen and Stephen Moore, «May We Cut In, Mr. Clinton? A Plan to Balance the Budget Without Raising Taxes», Policy Review, Spring 93, no 64, pp. 4-11.

${ }^{16}$ Ver VALCÁRCEL, Darío, «La América de Clinton: peligros del aislamiento, riesgos del liderazgo», p. 9.

${ }^{17}$ Las leyes y transformaciones que lograron eran cuestiones menores, tales como la prohibición del uso de armas de asalto y la reducción de las armas cortas (Ley Brady); el aumento hasta 1.000 dólares del crédito fiscal para familias con ingresos menores de 23.500 dólares; el compromiso de vacunar a todos los niños de la nación menores de dos años; el compromiso de proporcionar préstamos de bajo interés a la clase media y estudiantes; el Programa de Servicio Nacional, para que los jóvenes sirvan en cometidos de interés público; el proyecto para llegar a una reducción de unos 100.000 funcionarios en los departamentos federales, etc. Ver PALOMARES, Gustavo, «La era de Clinton», Cuadernos del Mundo Actual, n99, Historia 16, Madrid, 1995, p. 23.

${ }^{18}$ Especialmente las infidelidades del presidente y el escándalo Whitewater, un complejo entramado político-financiero en el que se vio envuelta la mujer de Clinton, Hillary, quien fue acusada de intervenir en una operación especulativa en el periodo en que su marido era gobernador de Arkansas. Ver: Ver PALOMARES, Gustavo, «La era de Clinton», p. 23.

${ }^{19}$ Bajo el liderazgo del congresista georgiano Newt Gingrich, los republicanos recuperaron el control del Senado y se impusieron, tras cuarenta años, en la Cámara de Representantes. A partir de ese momento, los demócratas han tenido que llegar a importantes acuerdos bipartidistas mediante la adopción de políticas del programa republicano. Ver COLOMER, Joseph, «El legado 'liberal-liberal' de Clinton», El País, 26 de febrero de 1999, p. 15 y PALOMARES, Gustavo, «La era de Clinton», p. 30.
} 
Fue el momento en el que decidió la estrategia de ocupar claramente el centro político (presentó una Carta de derechos de la clase media), pero simultáneamente seguía una contrast politic ${ }^{20}$ con los republicanos, tratando distanciarse de ellos en los asuntos de seguridad ciudadana, programas sociales y política exterior. Utilizó dos estrategias que le han servido a lo largo de su mandato. Por un lado se posicionó tomando distancia de los republicanos y demócratas del Congreso para definirse en referencia a ellos. Y por otro lado, dentro de su partido, se distanció tanto de los «liberales» (en sentido norteamericano) como de los «nuevos demócratas» (centristas). La estrategia era asumir objetivos de la oposición para desmotivarlos, lo que hizo que los republicanos también giraran hacia el centro y propusieran programas de política social ${ }^{21}$, denunciando repetidamente que Clinton les había robado su programa.

El éxito de Clinton ha sido borrar las líneas de separación entre los dos partidos y distanciarse de ambos. Empezó pidiendo más gobierno en forma de más gasto en su discurso sobre el estado de la Unión de 1993, para en su intervención en el estado de la Unión de 1996 señalar que «la era del gran gobierno había acabado», dando hilo a la cometa del equilibrio presupuestario mediante recortes en los gastos con nuevos controles sobre los programas sociales, pero con una simultanea reducción de impuestos $^{22}$. Esta estrategia de Clinton llevó a que los republicanos no tuvieran mucho que reprocharle. Ha promovido el libre comercio internacional iniciando un proceso de globalización económico en expansión; ha conseguido la aprobación de una serie de presupuestos equilibrados (logrando el superávit presupuestario ${ }^{23}$ );

${ }^{20}$ Ver DELAGE, Fernando, «Estados Unidos los próximos cuatro años», Politica Exterior, Vol. $\mathrm{X}, \mathrm{n}^{\circ} 54$, p. 82.

${ }^{21}$ Situación que varió con la candidatura a la presidencia de Dole, pero que se ha impulsado en estas últimas elecciones del 2000 con el llamado "conservadurismo compasivo» de George W. Bush a la presidencia. Su propuesta no se aleja de la idea de reducción del peso del Gobierno en la vida de los norteamericanos, pero ha añadido el concepto de «compasión», que trata de poner énfasis en la intervención pública para la enseñanza primaria, las pensiones de jubilación y la cobertura farmacéutica de los ancianos. Esto ha llevado a que se generalizase, todavía más, la idea de que no existe una gran diferencia programática entre los demócratas y los republicanos. Sin embargo, pese a sus coincidencias y a que no representan ninguna nueva visión de nada, tratan de resolver de modo distinto problemas concretos.

${ }^{22}$ Ver DELAGE, Fernando, «Estados Unidos los próximos cuatro años», Política Exterior, Vol. $\mathrm{X}, \mathrm{n}^{\circ} 54$, p. 89.

${ }^{23}$ Algo que había prometido Reagan pero que no cumplió, lo logró Clinton en el ejercicio físcal de 1998 con la complicidad de un ciclo económico en crecimiento durante 82 meses; ver, El País, 5 de febrero de 1998, p. 10. Para el superávit del año 1999, Clinton fue mucho más conciso, y argumentó que se dedicaría a la seguridad social y al Medicare (asistencia sanitaria a ancianos), mejoras a la educación y reducir deuda pública; ver El País, 2 de febrero de 1999, p. 52. Aunque también se 
y ha suprimido los subsidios públicos a los parados que demuestran ser capaces de trabajar. El resultado es que EEUU se encuentra en un periodo de prosperidad económica de una duración sin precedentes, con un nivel de empleo y ritmo de crecimiento superiores a los de Europa ${ }^{24}$. A pesar de estos datos favorecedores, hay algunos nubarrones que pueden hacer pinchar la enorme burbuja en la permanece la economía estadounidense, ya sea en un «aterrizaje suave» o mediante un colapso más brusco. Los datos para la preocupación se centran en el inmenso déficit comercial con un alarmante aumento de exportaciones; el descenso del ahorro (durante el año 1999 se llegó al ahorro cero) ${ }^{25}$; la creciente población carcelaria del país, que camufla, en parte, los datos de empleo puesto que no cuentan como desempleados; y la desigualdad, puesto que en algunas empresas en las que se han repartido stock options (opciones sobre la compra de acciones), la diferencia entre el emolumento más alto y el más bajo ha alcanzado la relación de 419 a uno ${ }^{26}$.

Ante esto, los republicanos no tenían mucho que oponer a la política del presidente y optaron por desarrollar la iniciativa del ataque moral, centrada en la defensa de los valores familiares tradicionales, y explicitada en los escándalos sexuales de Clinton ${ }^{27}$

ha discutido la posibilidad de dedicar los remanentes económicos a comprar su propia deuda; ver $E l$ País, 5 de agosto de 1999, p. 40.

${ }^{24}$ Estados Unidos ha batido el récord de crecimiento económico de su historia. El crecimiento de los últimos años supera el 4\% (4,5\% en $1997 ; 4,3 \%$ en $1998 ; 4,1$ en 1999). El consumo está muy alto y equivale a dos tercios de la economía; la inflación la tienen controlada; el paro está en el 4,1\% (pleno empleo), hasta el punto de que los empresarios están exigiendo un replanteamiento más generoso de las leyes de emigración y de la situación de la situación de los casi seis millones de trabajadores ilegales. La productividad también ha subido un 2,9\% en 1999 y han disminuido los costes laborales en 1,2\%. Ver ESTEFANÍA, «La más larga etapa de expansión», El País, 27 de febrero de 2000, p. 60. Ver también: $A B C, 9$ de junio de 1998, p. 16; ORTEGA, Andrés, «¡A gastar, a gastar!», El País, 1 de febrero de 1999, p. 6; El País, 1 de mayo de 1999, p. 52; El País, 5 de junio de 1999, p. 68; El País, 6 de noviembre de 1999, p. 61; El País, 3 de febrero de 2000, p. 52; El País, 26 de febrero de 2000, p. 69; Suplemento «Nueva Economía», El Mundo, 16 de abril de 2000, p. 15.

${ }^{25}$ Aunque otros autores ven en el gasto de los consumidores como el factor que ha evitado la recesión en la economía de los Estados Unidos. Ver SAMUELSON, Robert J., «La muerte del ahorro», El Mundo, 2 de marzo de 1999, p. 44.

${ }^{26}$ Ver ESTEFANÍA, J., «La más larga etapa de expansión», El Pais, 27 de febrero de 2000, p. 60. Para una lectura crítica de estos datos, consultar: NAVARRO, Vincenç, Neoliberalismo y Estado de bienestar, Ariel, Barcelona, 1997.

27 Según Joseph Colomer, tres elementos institucionales explican el descarrío de la agenda pública hacia la vida personal del presidente Clinton desde enero de 1998. 1- La labor de la fiscalía especial, a la que se dotó de poderes ilimitados como reacción a los abusos de poder de Nixon durante el escándalo Watergate, y que ahora todos la consideran un error de diseño institucional; 2- La evolución de los medios de comunicación hacia el entretenimiento más que a la información; 3- La ausencia de liderazgo en el Partido Republicano, que ha sido dirigido desde fuera por grupos 
(especialmente el caso Lewinsky ${ }^{28}$ ). Debido al descabezamiento republicano ${ }^{29}$ el partido fue dirigido desde fuera. Semana tras semana se podía ver como los congresistas republicanos seguían las consignas de las revistas American Spectator y Weekly Standard ${ }^{30}$ y como la Coalición Cristiana y los neoconservadores ejercían una gran influencia en la estrategia política republicana. Entre los neoconservadores, destacó la labor de la familia ${ }^{31}$ de uno de sus fundadores, Irving Kristol ${ }^{32}$, quienes elaboraron una teoría intelectual que impulsó la campaña contra Clinton, y que tenía como eje la reflexión de que «los gobernantes deben ser elegidos entre las mejores personas en el aspecto moral y ser ejemplo y guía de conducta» $\aleph^{33}$.

Pero no todo han sido parabienes y algunos autores han apuntado algunos «peros» a la situación de euforia que vive Estados Unidos:

a) Paul Krugman ha señalado que ha habido una «racha favorable» en el ciclo económico ayudado por determinados factores temporales que han colabo-

como la Coalición Cristiana o los neoconservadores. Ver COLOMER, Joseph, «El legado 'liberalliberal' de Clinton», El País, 26 de febrero de 1999, p. 15.

${ }^{28}$ El tercer impeachment de la historia de los Estados Unidos se abrió el 19 de noviembre de 1998 en torno a las relaciones de Bill Clinton con Monica Lewinsky, antigua becaria de la casa blanca. Clinton era acusado de perjurio cuando declaró ante el gran jurado sobre sus relaciones con la becaria y por obstrucción de la justicia. Fue absuelto el 12 de febrero de 1999, lo que significó una gran derrota para los republicanos. Ver diario La Razón, 20 de noviembre de 1998, p. 23; diario El País, 13 de febrero de 1999, p. 2; diario El Mundo, 19 de diciembre de 1998, pp. 8-9. Tras ser absuelto, Clinton pidió perdón e invitó a la «reconciliación» (ver diario El País, 13 de febrero de 1999, p. 3; El Mundo, 13 de febrero de 1999, p. 20).

${ }^{29}$ Ford es considerado marginal, Reagan padece una enfermedad terminal, Bush está maniatado por las carreras políticas de sus hijos, y Newt Gingrich fracasó en las elecciones al Congreso en 1999 y dimitió. Ver COLOMER, Joseph, «El legado 'liberal-liberal' de Clinton», El País, 26 de febrero de 1999, p.15.

${ }^{30}$ Según Colomer: «dos revistillas con pocas páginas y escasa difusión fuera de Washington». COLOMER, Joseph, «El legado 'liberal-liberal' de Clinton», El País, 26 de febrero de 1999, p. 15.

${ }^{31}$ Especialmente su hijo, un propagandista incansable en los medios de comunicación (COLOMER, Joseph, «El legado 'liberal-liberal' de Clinton», El País, 26 de febrero de 1999, p. 15), y su mujer, la historiadora de los valores victorianos, Gertrude Himmelfarb, autora de HIMMELFARB, G., On liberty and liberalism: the case of John Stuart Mill, ICS, San Francisco, 1990; HIMMELFARB, Matrimonio y moral en la época victoriana y otros ensayos, Debate, Madrid, 1991; y en historiografía el muy comentado The new history and the old, Harvard University Press, Cambridge, 1987.

${ }^{32}$ Irving Kristol es el denominado «padrino del neoconservadurismo» y ha publicado en torno al particular Neoconservatism: the autobiography of an idea, New York, The Free Press, 1995.

33 Ver COLOMER, Joseph, «El legado 'liberal-liberal' de Clinton», El Pais, 26 de febrero de 1999, p.15.

Cuadernos de Estudios Gallegos, Tomo LI, Fascículo 117, Santiago 2004. (Págs. 375 - 403) 
rado a conservar baja la inflación. Paralelamente han contribuido los cambios en el mercado laboral, puesto que han reducido el poder reivindicativo de los trabajadores y han permitido un mayor empleo sin incrementar los salarios. Todo esto, apostillado con el retraso que han experimentado las economías asiáticas y europeas ${ }^{34}$.

b) La desigualdad. El nivel de vida del $10 \%$ más pobre de familias estadounidenses es más bajo en la actualidad que hace una generación. Las familias de estrato medio, en el mejor de los casos, poseen un nivel ligeramente más acomodado. Sólo el $20 \%$ más opulento de los norteamericanos han conseguido un crecimiento de la renta a unas tasas como las que experimentaron casi todos entre los años cuarenta y primeros setenta. Las rentas de las familias del estrato superior han aumentado extraordinariamente. La reducción de los impuestos de las rentas más altas y los programas sociales para los perceptores de las rentas más bajas comenzó con Reagan, pero la mayor parte del crecimiento de la desigualdad se produjo en el mercado y en las rentas de las familias antes de pagar impuestos ${ }^{35}$. El economista Luis de Sebastián recoge en su libro El rey desnudo ${ }^{36}$ los datos de la Oficina del Censo de los Estados Unidos con relación a la pobreza. En 1997 había en el país 35,6 millones de personas considerados pobres. Son consideradas pobres las personas que viven por debajo de la línea establecida en 16.400 dólares para una familia de cuatro personas. Alcanzaban el 13,3\% de la población censada. Según De Sebastián la pobreza ha aumentado desde 1989 hasta 1997 en 3,2 millones de personas. Y la tasa de pobreza es mayor que hace treinta años. También son preocupantes los datos sobre las personas que no disfrutan de seguridad médica, en torno a los 40 millones de personas (el $15,4 \%$ de la población). Entre los inmigrantes la pobreza se mantenía en 1997 en un $22,2 \%$.

c) La regresión cultural. Enmanuel Todd ${ }^{37}$ observa una regresión cultural en los Estados Unidos en el capítulo de licenciados. Es un descenso que afecta

\footnotetext{
${ }^{34}$ Ver KRUGMAN, Paul, «La falsedad de la nueva economía», Política Exterior, $\mathrm{n}^{\circ}$ 65, Vol. XII, Septiembre/Octubre 1998, pp. 15-169.

${ }^{35}$ Ver KRUGMAN, Paul, El teórico accidental y otras noticias de la ciencia lúgubre, Crítica, Barcelona, 1999.

${ }^{36}$ SEBASTIÁN, Luis de, El rey desnudo. Cuatro verdades sobre el mercado, Editorial Trotta, Madrid, 1999.

${ }^{37}$ TODD, Emmanuele, La ilusión económica. Sobre el estancamiento de las sociedades desarrolladas, Taurus, Madrid, 1999.
} 
a todos los grupos étnicos y raciales que constituyen la sociedad americana. Parece que se ha alcanzado un techo cultural y que no se podrá superar. Podría pensarse que estos datos están compensados con una mayor calidad pero tampoco es así, y el nivel intelectual americano ha bajado considerablemente desde los años 50. Esta explicación sirve para entender mejor los múltiples fenómenos regresivos que han tenido lugar en los Estados Unidos en las décadas 70, 80 y 90. Las dificultades económicas, la provincialización intelectual y artística, el surgimiento de un cine de acción y violento, el desarrollo de ciencias sociales e históricas absurdas que ponen en el centro de sus preocupaciones el conflicto entre hombres y mujeres, la obsesión por el acoso sexual, la puesta en cuestión del aborto, el regreso de los creacionistas hostiles a Darwin y a la evolución de las especies, la degradación jurídica y represiva, con un número de individuos purgando sus penas en prisión o en otra parte, que pasó entre 1980 y 1993 , de 1.840 .400 a $4.879 .600^{38}$. A esto hay que añadir la pena de muerte. El número de presos que espera su ejecución aumentó entre 1980 y 1994, de 688 a 2.890. La regresión cultural puede debilitar el progreso tecnológico. Todd también analiza la baja productividad, la alta mortalidad infantil, el retroceso en la base industrial y el aumento del consumo, así como el «fraude sanitario».

d) Otros autores, como es el caso de Fred Mosely ${ }^{39}$, argumentan que Estados Unidos no está en una época de prosperidad, puesto que los beneficios han caído desde los años de posguera en un 30-40\%, y los salarios lo han hecho en un $20 \%$ desde los años 70 . Moseley también sostiene que parte del crecimiento se ha debido al incremento de la circulación del capital extranjero (que provocó la recesión asiática).

Tampoco Clinton ha entregado en la asignatura de política exterior unas notas demasiado favorables. No es cuestión, como argumentaba Martin Woolacott en agosto de $1998^{40}$, de que Estados Unidos sean los culpables de todo lo que pase sobre la tierra, pero en caso de que el presidente decidiera bajo la perspectiva del «largo plazo» y no buscando sólo el «provecho inmediato» y aplazando las cues-

\footnotetext{
${ }^{38}$ Para una reflexión más en profundidar, consultar ORTEGA, Andrés, «Encarcelar el problema», El País, 20 de abril de 1998, p. 12.

${ }^{39}$ MOSELEY, Fred, «The United States economy at the turn of the century: entering a new era of prosperity?», Capital \& Class, nº7, Spring 1999, pp. 25-46.

${ }^{40}$ WOOLACOTT, Martin, «Clinton y su naufragio», El Mundo, 25 de Agosto de 1998, p. 15.
} 
tiones difíciles ${ }^{41}$, pudiera haber sido el primero en percatarse del desastroso impacto de las reformas económicas occidentales en Rusia o de la debilidad real de las economías del sureste asiático. También habría estado más ágil en las negociaciones para el desarme nuclear con el fin de evitar los ensayos atómicos de Pakistán, India y Francia. Por no hablar del bloqueo sobre Cuba y las sanciones Irak y otros países islámicos.

Pero el caso más delicado al que se enfrentó la Administración Clinton fue el los bombardeos sobre Yugoslavia, donde Estados Unidos exhibieron todo su poderío militar y su reafirmación imperialista. «El castigo es un fin en sí mismo; bombardear para exhibir le poder de la OTAN es de por sí satisfactorio, especialmente cuando hay pocas probabilidades de sufrir represalias», asegura el profesor de la universidad de Columbia Edward Said ${ }^{42}$, quien continúa: «ninguna nación que sea atacada por el aire apoyará a los agresores. En todo caso, el régimen de Milosevic ha sido reforzado. Todos los serbios piensan que su país está siendo atacado injustamente, y la guerra cobarde que se libra contra ellos los hace sentirse perseguidos $\rangle^{43}$.

Para el especialista en relaciones internacionales, Ignacio Ramonet, la guerra que enfrentó a la Organización del tratado del Atlántico Norte (OTAN) con la República Federal de Yugoslavia, abre una nueva etapa en la historia de las relaciones internacionales, al justificar mediante argumentos de orden humanitario la trasgresión de dos de los presupuestos capitales en la política internacional: la soberanía de los Estados y el estatus de la Organización de Naciones Unidas ${ }^{44}$. A juicio de Ramonet avanzamos desde un Estado-nación a un Estado-individuo. Los bombardeos fueron decididos por la OTAN sin que ninguna resolución del Consejo de Seguridad de la ONU las autorizara explícitamente. Fue la primera vez que se marginó a las Naciones Unidas, «la única plataforma internacional para la resolución de los conflictos y el mantenimiento de la paz», asegura Ramonet.

\footnotetext{
${ }^{41}$ Sobre la política exterior, cabe reseñar que muchos estadounidenses expertos en política y, sobre todo, en derecho constitucional, han señalado más de una vez que el actual sistema de elecciones cada dos años a la Cámara de Representantes y al Senado (aunque la que se realiza al mitad del mandato determina sólo la mayoría de la Cámara y la composición del Senado), entorpecen la capacidad para la política internacional. Cuando se empieza a trabajar ya hay que estar pensando en la siguiente elección. Para profundizar en esta reflexión, consultar HABSBURGO, Otto, «El gigante debilitado", $A B C, 3$ de junio de 1998, p. 40.

${ }^{42}$ Ver SAID, Edward, «Es hora de que el mundo haga frente al matón americano», El Mundo, 15 de abril de 1999.

${ }^{43}$ Ver SAID, Edward, «Es hora de que el mundo haga frente al matón americano»

${ }^{44}$ RAMONET, Ignacio «Nuevo orden global», Le Monde Diplomatique, año IV, $\mathrm{n}^{\circ} 44$, junio de 1999, p. 1.
} 
Para Ramonet, todo indica que Estados Unidos ya no se adapta a Naciones Unidas $^{45}$, en su situación de actual hegemonía. «Estados Unidos no entiende por qué ha de compartir o limitar su hegemonía, cuando la puede ejercer plenamente sin que nadie (incluida Naciones Unidas) pueda cuestionarla», cerciora Ramonet ${ }^{46}$.

Por último, es necesario hacer mención de las protestas que ha tenido que soportar la Estados Unidos y en general los agentes de la globalización desde 1999 con las manifestaciones antiglobalización que se sucedieron en Seattle ${ }^{47}$, Davos y Praga Seattle, Davos, Washington, Bangkok, Praga, Niza, Quebec, Gotemburgo, y Génova, y que tuvieron una serie de replicas en el juico al líder agrario Bovét8 y en la asamblea del Banco Mundial y $\mathrm{FMI}^{49}$. Estos movimientos, sobre todo el de Seattle, fueron un punto de inflexión. En una década de cambio tecnológico y globalización se incrementaron la desigualdad, la pobreza y la exclusión social en la mayor parte del mundo. Más de dos terceras partes de la humanidad no se benefician del nuevo modelo de crecimiento económico. Internet llega a menos de un $3 \%$ de la población y los desequilibrios ecológicos se han agravado. «Y esto es así porque, en lo esencial, el incremento del comercio internacional y el desarrollo de las nuevas tecnologías se ha regido prioritariamente por mecanismos de marcado», escribe Manuel Castells en un riguroso artículo ${ }^{50}$. «Lo que era la gran apuesta de Clinton para pasar a la historia en el cambio de milenio como el actor clave de

${ }^{45}$ Numerosos indicios registrados desde le comienzo de la década de los 90 indicaban que Estados Unidos no deseaba que la ONU cumpliese su papel: la no renovación de Butros Gali por un más sensible a las tesis de Washington, Kofi Annan; la firma de los Acuerdos de Dayton sobre Bosnia bajo la égida americana y no de la ONU; los acuerdos palestinos de Wye Plantation; o la decisión unilateral de bombardear Irak sin la decisión de la ONU. Ver RAMONET, Ignacio «Nuevo orden global», Le Monde Diplomatique, año IV, $\mathrm{n}^{\circ}$ 44, junio de 1999, pp. 16.

${ }^{46}$ RAMONET, Ignacio «Nuevo orden global», Le Monde Diplomatique, año IV, $\mathrm{n}^{\circ} 44$, junio de 1999, pp. 16. No se trata sólo de una opinión. En el diario El Mundo del miércoles 9 de diciembre de 1998, su corresponsal en Bruselas, Carlos Segovia, se hacía eco de unas manifestaciones de la secretaria de Estado estadounidense, donde planteaba formalmente crear una nueva OTAN que pudiera actuar sin permiso expreso del Consejo de Seguridad de Naciones Unidas. El Mundo, 9 de diciembre de 1998, p. 16.

${ }^{47}$ Unos 50.000 manifestantes se hicieron escuchar en Seattle. Una coalición de ONG's, ecologistas, fuerzas sindicales y grupos de presión agrícolas influyeron en el fracaso de la llamada «Ronda del Milenio» (que había organizado Clinton) para acelerar la liberalización del Comercio Mundial especialmente en los sectores servicios y agricultura e industrial. Países ricos y pobres no se pusieron de acuerdo y aplazaron sine die la Ronda del Milenio. Ver diario EL Mundo, 5 de diciembre de 1999, pp. 14 y 47; El País, 5 de diciembre de 1999, p. 6.

${ }^{48}$ Ver Diario 16, 1 de julio de 2000, p. 31.

${ }^{49}$ Ver diario El Mundo, 18 de abril de 2000, p. 43; El País, 17 de abril de 2000, p. 71.

${ }^{50}$ CASTELLS, Manuel, «Seattle y el cinismo neoliberal», El País, 3 de enero de 2000, p. 13. 
la globalización se ha convertido en la crisis de una Organización Mundial de Comercio semisecreta y en la crisis de la hegemonía americana para dictar los términos de la globalización». Castells termina afirmancdo que la globalización «será democrática, informada y controlada por la gente o no será».

Clinton ha sido el presidente que ha marcado la agenda ideológica internacional hacia la izquierda moderada durante su mandato, con los presupuestos de la llamada "Tercera vía», un intento de casar el liberalismo con la justicia social. Alrededor de Clinton se ha tejido esa red de dirigentes progresistas que han intentado dar respuesta a la globalización. También ha supuesto la intervención del Partido Demócrata en los debates de la izquierda ${ }^{51}$.

\section{EL CASO EUROPEO}

En cuanto a la situación al otro lado del atlántico, en la Europa de los 15 el «momento progresista», como se ha dicho más arriba, cristalizó en 1998 con las victorias de Schröeder en Alemania y D’Alema en Italia. Sólo Irlanda y España quedaban como países no gobernados por los socialdemócratas. A pesar de este dominio, algunos observadores ${ }^{52}$ se preguntaban qué había cambiado en la política económica desde que los principales países europeos fueron gobernados por Jospin, Blair, Schröder o D'Alema. Se notaba una cierta falta de reflejos en los cambios, especialmente para la construcción de una Europa social. Se apreciaba una unidad en el diagnóstico del paro como el gran problema europeo, pero se pulsaba una gran división en las soluciones. Cada país lo resolvió considerando sus problemas nacionales y sólo en Francia se llevó a cabo un tratamiento contundente con la propuesta de reducción de la semana laboral a 35 horas $^{53}$. Los demás partidos so-

${ }^{51}$ Siguiendo a Andrés Ortega. Ver ORTEGA, Andrés, «Efectos ideológicos», El País, 6 de noviembre de 2000 , p. 4 . Ortega también señala que el gobierno español, encabezado por su presidente José María Aznar, ha intentado, sin éxito, integrarse en ese conjunto de gobiernos progresistas, puesto que es un «club» vetado a gobiernos socialdemócratas.

${ }^{52}$ Es el caso de Joaquín Estefanía en «socialconformismo», El País, 12 de septiembre de 1999, p. 59.

${ }^{53}$ Se realizó bajo la coordinación de la ministra francesa de Empleo y Solidaridad, Martine Aubry. La misma ministra visitó Madrid en marzo de 1998 para dictar una conferencia y allí dio esa impresión de desunión. Al ser preguntada por si la medida de las 35 horas era aplicable a España, señaló que «no existen recetas universales y depende de la correlación de fuerzas en la sociedad española». Declaraciones recogidas en: ESTEFANÍA, Joaquín, «Lecciones de Aubry», El País, 22 de marzo de 1998, p. 54.

Cuadernos de Estudios Gallegos, Tomo LI, Fascículo 117, Santiago 2004. (Págs. 375 - 403) 
cialdemócratas se han mostrado divididos al respecto. Jospin con unas formas y Blair y Schröder con otras, como se explicitó cuando éstos firmaron el «manifiesto de la tercera vía», se han plegado a la coyuntura de sus países y cada uno intentó buscar sus soluciones ${ }^{54}$.

\subsection{EI Reino Unido}

Más allá de las divisiones, Lionel Jospin y Tony Blair representan las caras del socialismo moderno europeo. Este último ganó arrolladoramente las elecciones del Reino Unido en 1997 y ha sido el que se ha preocupado más por ofrecer un cuerpo ideológico a su programa de centro radical (también puede ser considerado una ampliación de las políticas neoliberales de los años 80), que se ha llamado «Tercera Vía» ${ }^{55}$ y en el que fue asesorado por el director de la London School of Economics y sociólogo Anthony Giddens ${ }^{56}$. De repente «todo el mundo quería ser Blair». Incluso en Le Monde se publicó una viñeta donde se veía a Chirac, Juppé y Jospin bajo el mismo epígrafe: «C'est moi. Tony Blair» ${ }^{57}$.

Blair ha intentado conservar lo mejor de la etapa de Thatcher y Major ${ }^{58} \mathrm{y}$, a la vez, ha intentado plantear los postulados de un laborismo reformado, basado en la existencia de un salario mínimo, la integración de Gran Bretaña en la Carta Social Europea, la autonomía económica del Banco de Inglaterra, la autonomía a Escocia

\footnotetext{
${ }^{54}$ Para más profundización, léase: ESTEFANÍA, Joaquín, «socialconformismo», El País, 12 de septiembre de 1999, p. 59.

${ }^{55}$ Incluso llegó a publicar un libro al respecto: BLAIR, Tony, La tercera vía. Nueva política para un nuevo siglo, El País/Aguilar, Madrid, 1998. La traducción española del libro incluía un prólogo de el, por aquel entonces, portavoz socialista en el Parlamento y candidato a la presidencia del Gobierno por el PSOE, José Borrell. En aquellos meses tanto el PSOE como el PP, en la figura del presidente del Gobierno José María Aznar, se disputaban, siguiendo el ejemplo de casi toda Europa, el parentesco con la «Tercera Vía». Así, Aznar presentó diversas propuestas en el Parlamento Europeo en compañía de Blair y es conocida su gran sintonía personal. Ver ESTEFANÍA, Joaquín, «¿De quién es Blair?», El País, 15 de noviembre de 1998, p. 60, y El Mundo, 19 de marzo de 2000, p. 24. Un ejemplo práctico de colaboración se puede ver en el artículo: Tony Blair y José María Aznar, «El crecimiento, objetivo esencia para Europa», El Mundo, 13 de junio de 2000, pp. 4-5.

${ }^{56}$ Quién a partir de sus trabajos como Más allá de la izquierda y la derecha. El futuro de las políticas radicales, cuajó intelectualmente esa «Tercera Vía», que ha paseado por todo el mundo Blair. La expresó en papel unos meses después de que saliera a la venta el libro de Blair. Sus señas son: GIDDENS, Anthony, La tercera vía. La renovación de la socialdemocracia, Taurus, Madrid, 1999. Después se ha seguido dedicando al tema y ha publicado GUIDDENS, Anthony, Un mundo desbocado. Los efectos de la globalización en nuestras vidas, Taurus, Madrid, 2000.

${ }^{57}$ Ver ESTEFANÍA, Joaquín, Contra el pensamiento único, p. 328.

${ }^{58}$ Cuestión que le ha servido para que le llamen Tory Blair. Ver ESTEFANÍA, Joaquín, Contra el pensamiento único, p. 230.
} 
y Gales, la distancia crítica con los sindicatos, y con la novedad de la integración la Unión Europea y el euro.

Blair y los nuevos laboristas buscan el espacio intermedio entre el Estado y el mercado, insisten en que la globalización de la economía tiene muchas potencialidades, pero también peligros de incrementar la dualidad en las sociedades del Primer Mundo y de ampliar las desigualdades entre Primer y Tercer Mundo. Defienden una profunda reforma del Estado de bienestar y defienden la dureza contra la delincuencia ${ }^{59}$. A nivel general, no dista demasiado de lo que se ha visto en el programa de Bill Clinton ${ }^{60}$. En este sentido una de las primeras medidas por las que optó Blair ${ }^{61}$, siguiendo a Clinton, y a los que seguiría más tarde Jospin, fue dedicar unas partidas presupuestarias extras a enderezar la situación de la Sanidad y Educación, donde incidieron en la idea de una educación permanente y adecuada a las nuevas necesidades, con el objetivo de paliar los porcentajes de paro, y ayudar a eliminar la marginalidad y la pobreza, aunque se mantengan los objetivos de inflación, gasto público y privatizaciones del pasado ${ }^{62}$.

Pero, ¿qué es la «Tercera Vía»? Para su teórico, el sociólogo Anthony Giddens, el término no tiene «particular significación en sí mismo ni por sí mismo. Ha sido utilizado anteriormente muchas veces en la historia de la socialdemocracia, y también por escritores y políticos de tendencias bastante diferentes ${ }^{63}$. Giddens hace uso de él para referirse a la renovación de la socialdemocracia, y asegura que la «Tercera Vía» ha acabado asociándose a la política de Tony Blair y al Nuevo Laborismo, que ha sido comparado frecuentemente con la retórica e influencias de los Nuevos Demócratas en Estados Unidos. Guiddens explica que ha habido contactos frecuentes y que parte de la renovación que ha impulsado el Nuevo Laborismo se ha desarrollado de espaldas a la socialdemocracia continental. «En lugar de simplemente apropiarse de pautas y nociones americanas, Gran Bretaña podría

${ }^{59}$ Ver ESTEFANÍA, Joaquín, Contra el pensamiento único, p. 231.

${ }^{60}$ Haciendo una acotación para España, Estefanía hace notar, nadando hacia su orilla, que es algo que hizo el Felipe González de 1982. Ver ESTEFANÍA, Joaquín, Contra el pensamiento único, Taurus, Madrid, 1997, p. 232. Es curiosa la obsesión de Estefanía con otorgarle las ideas de la «Tercera Vía» a González, ver: ESTEFANÍA, J., «La Tercera Vía como pensamiento único», El País, 25 de julio de 1999, p. 48.

${ }^{61}$ Blair incluso organizó una conferencia en New York donde reunió a Bill Clinton y a Romano Prodi. Ver TOURAINE, Alain, ¿Cómo salir del liberalismo?, Paidós, Barcelona, 1999, p. 96.

${ }^{62}$ Ver ESTEFANÍA, Joaquín, Contra el pensamiento único, p. 327.

${ }^{63}$ GUIDDENS, Anthony, La tercera vía. La renovación de la socialdemocracia, Taurus, Madrid, 1999, pp. 6-7. En el caso español, se denominó «Tercera Vía» al camino falangista de superación del capitalismo y comunismo. Ver ESTEFANÍA, Joaquín, «¿Tercera Vía o progreso global?», El País, 29 de noviembre de 1998, p. 61. 
actuar de catalizador en la interacción creativa entre Estados Unidos y Europa Occidental $»^{64}$, aclara Guiddens, quien es plenamente consciente que la «Tercera Vía» ha sido vista como un «neoliberalismo recalentado».

La intención es «tender puentes», en palabras de Tony Blair ${ }^{65}$, entre la familia de los socialistas y los socialdemócratas europeos y el Partido Demócrata en Estados Unidos. Aunque conviene advertir que esta iniciativa de la «Tercera Vía» se nutre de la relación especial histórica entre Londres y Washington, y que la «Tercera Vía» que propugna el actual primer ministro del Reino Unido es la respuesta británica del Nuevo Laborismo frente al viejo partido estatalista y ante el neoliberalismo thatcheriano.

Tony Blair, que ha llevado a la práctica la «Tercera Vía» ${ }^{66}$, la define como «la mejor etiqueta para la nueva política que el centro-izquierda progresista está forjando en Gran Bretaña y en otras naciones. La Tercera Vía aboga por una socialdemocracia modernizada, apasionada en su compromiso con la justicia social y con las metas del centro-izquierda, pero al mismo tiempo flexible, innovadora y con visión de futuro a la hora de conseguir estos objetivos. La Tercera Vía se basa en los valores que han guiado a la política progresista durante más de un siglo: democracia, libertad, justicia, compromiso mutuo e internacionalismo. Pero es una Tercera Vía porque trasciende a una vieja izquierda preocupada por el control del Estado, los elevados impuestos y los intereses de los productores; y a una nueva derecha que considera la inversión pública y, a menudo, el concepto de sociedad y de esfuerzo colectivo como males que hay que superar» ${ }^{67}$. Asimismo, Blair en su

${ }^{64}$ GUIDDENS, Anthony, La tercera vía. La renovación de la socialdemocracia, p. 9. Unas páginas más adelante añade que «la expresión parece haberse acuñado ya a finales del siglo pasado, y fue común entre los grupos de derechas en los años veinte. Sin embargo ha sido utilizada mayormente por socialdemócratas y socialistas. A comienzos del periodo de posguerra los socialdemócratas estaban convencidos de que estaban encontrando una vía distinta al capitalismo de mercado norteamericano y al comunismo soviético. En el momento de su refundación en 1951, la Internacional Socialista hablaba explícitamente de la tercera vía en este sentido. Unos veinte años más tarde, tal y como fue usada por el economista checo Ota Sik y otros, se empleó para referirse al socialismo de mercado. A finales de los ochenta los socialdemócratas suecos parecen haber hablado con más frecuencia de la tercera vía, para referirse a una importante renovación programática». Ver La tercera vía. La renovación de la socialdemocracia, p. 37.

${ }^{65}$ Ver El País, 8 de abril de 1998, pp. 10.

${ }^{66}$ Para una evaluación de lo que ha hecho en sus primeros meses de gobierno, ver: BRAY, Nicholas, «Tony Blair y el nuevo laborismo», Política Exterior, 58, XI, Julio-Agosto 1997, pp. 11-21.

${ }^{67}$ BLAIR, Tony, La Tercera Via, pp. 53-54. Hay diferentes artículos que resumen algunas de las ideas: BLAIR, Tony, «La Tercera Vía, una democracia social moderna», El País, 21 de septiembre de 1998, p. 15; BLAIR, Tony, «El new deal del laborismo», El Mundo, 2 de junio de 1998, p. 4-5. 
breve opúsculo explica que la «Tercera Vía» no es un intento de señalar las diferencias entre derecha e izquierda ${ }^{68}$, sino que se nutre de la unión de las dos grandes corrientes de pensamiento del centro-izquierda, el socialismo democrático y el liberalismo estadounidense. Pretende ser una «Tercera Vía» dentro de la propia izquierda, al ser una «seria revaluación de la socialdemocracia que profundiza en los valores de la izquierda para desarrollar enfoques radicalmente nuevos ${ }^{69}$, en palabras de Blair.

Esta cuestión de derecha/izquierda la trata más ampliamente, como corresponde, Guiddens, quien considera que con la caída del socialismo como teoría de gestión económica «ha desaparecido una de las principales líneas divisorias entre izquierda y derecha, al menos para el futuro inmediato (...) Nadie tiene ya alternativas al capitalismo (...) Al haber mudado estas circunstancias, se ha puesto de relieve toda una gama de problemas y posibilidades nuevas que no están al alcance del esquema izquierda/derecha. Éstos incluyen cuestiones ecológicas, pero también asuntos que tienen que ver con la naturaleza cambiante de la familia, el trabajo y la identidad personal y cultural. Por supuesto, los valores de justicia social y emancipación están conectados a ellos» ${ }^{70}$. Con esta reflexión pretende resituar a la izquierda alrededor de lo que denomina "centro radical», «centro izquierda»o «medio activo», dotando así de contenido el «centro» ${ }^{71}$.

La «Tercera Vía» aboga por un cambio en los valores. Pretende diluir la idea de «igualdad» y sustituirla por las de «reparto equitativo de riqueza», «igualdad de oportunidades», «solidaridad»y, sobre todo, «responsabilidad», mediante la cual se pretende que el ciudadano no sólo tenga derechos respecto al Estado, sino también deberes. Guiddens evoca la tradicional diferencia entre la derecha y la izquierda respecto a la «igualdad». Mientras que la izquierda favorece una mayor igualdad, la derecha ve la sociedad innatamente jerárquica. Pero piensa que esa «igualdad»o «justicia social» debe ser cambiada y definida en relación a creer en una política de la emancipación, es decir, la «igualdad» es relevante para las oportunidades vitales, el bienestar y la autoestima personal. Lo que busca Guiddens es una nueva relación entre individuo y comunidad, una redefinición de derechos y

\footnotetext{
${ }^{68}$ Dando abono para el reflorecimiento de teorías como la del fin de las ideologías (Daniel Bell) o el aposentamiento de la de «el fin de la Historia» (Fukuyama).

${ }^{69}$ BLAIR, Tony, La Tercera Via, El País/Aguilar, Madrid, 1998, pp. 56.

${ }^{70}$ GUIDDENS, Anthony, La tercera vía. La renovación de la socialdemocracia, p. 57.

${ }^{71}$ De ahí que muchos llamen a la «Tercera Vía» la izquierda de «el fin de la Historia», puesto que acepta el triunfo del capitalismo, asume la globalización y la descohesión social internacional, pero se sitúa críticamente a la izquierda.
} 
obligaciones, lo que le lleva al lema principal de la «Tercera Vía»: «ningún derecho sin responsabilidad ${ }^{72}$. Este planteamiento le ofrece las posibilidades suficientes para cambiar de vocabulario y redefinir la «igualdad» como «inclusión» y la desigualdad como «exclusión», de tal modo que la «inclusión» estaría definida en ese marco de nuevas relaciones entre la «igualdad» y la «libertad» y se referiría a los derechos y deberes civiles y políticos de todos los miembros de una sociedad, las oportunidades y la integración en el espacio público, el trabajo y la educación. Todo para integrar, efectivamente, lo que el llama «igualdad» con lo que los liberales estadounidenses denominan «igualdad de oportunidades» o «meritocracia».

Guiddens desarrolla otros puntos para guiar a los ciudadanos en las grandes revoluciones de nuestro tiempo: la globalización, las transformaciones de la vida personal y la relación con la naturaleza. En especial conviene pararse en la globalización, de la que dice que no se debe identificar con un apoyo universal al libre comercio ${ }^{73}$ y que la concibe como un proceso mucho más allá de lo económico, ya que «no es sólo, ni principalmente, interdependencia económica, sino la transformación del tiempo y del espacio en nuestras vidas» ${ }^{74}$. Con esta definición, Guiddens se aparta de determinadas posturas de la izquierda que ven la globalización como un mito o una continuación de tendencias establecidas hace tiempo (la globalización sería un invento de los neoliberales), y también se desmarca de aquellos que proclaman que vivimos en un mundo sin fronteras donde el Estado-nación ha prácticamente desaparecido y los políticos han perdido todo poder efectivo.

Dejando a un lado aspectos concretos y a modo de síntesis, Guiddens piensa que los valores centrales de la «Tercera Vía» deben ser: igualdad, protección de los débiles, libertad como autonomía, ningún derecho sin responsabilidad, ninguna autoridad sin democracia, pluralismo cosmopolita y conservadurismo filosófico ${ }^{75}$.

En cuanto al programa político de la «Tercera Vía», Guiddens también es claro. Los puntos claves son ${ }^{76}$ : el centro radical, el nuevo Estado democrático (el Estado

\footnotetext{
${ }^{72}$ GUIDDENS, Anthony, La tercera vía. La renovación de la socialdemocracia, pp. 81.

${ }^{73}$ Concreta esta explicación diciendo que «el libre comercio puede ser un motor del desarrollo económico, pero dado el poder social y culturalmente destructivo de los mercados, sus consecuencias más generales han de ser siempre examinadas», ver GUIDDENS, Anthony, La tercera vía. La renovación de la socialdemocracia, p. 80.

${ }^{74}$ Se refiere a que acontecimientos lejanos, económicos o no, nos afectan más directa o indirectamente que nunca y las decisiones que tomamos como individuos tienen, con frecuencia, implicaciones globales. Ver GUIDDENS, Anthony, La tercera vía. La renovación de la socialdemocracia, p. 43.

${ }^{75}$ Ver GUIDDENS, Anthony, La tercera vía. La renovación de la socialdemocracia, p. 82

${ }^{76}$ Consultar GUIDDENS, Anthony, La tercera vía. La renovación de la socialdemocracia, p. 86.
} 
sin enemigos), una sociedad civil activa, la familia democrática, la nueva economía mixta, igualdad como inclusión, bienestar positivo, el Estado social inversor, la nación cosmopolita y la democracia cosmopolita.

Esta serie de puntos claves, los ha expresado de una forma más pragmática Blair en su opúsculo sobre la «Tercera Vía»" ${ }^{77}$ 1- Una economía dinámica, basada en el conocimiento, edificada sobre la base de las oportunidades y el fortalecimiento individuales, en la que los gobiernos faciliten, no impongan, y en la que el poder del mercado sirva a los intereses públicos; 2- Una sociedad civil fuerte que asuma derechos y deberes, en la que el Gobierno y la ciudadanía colaboren estrechamente; 3- Un Gobierno moderno basado en la colaboración y la descentralización, que profundice en la democracia para adecuarla a los tiempos actuales; 4- Una política exterior basada en la cooperación internacional.

Ha surgido un enorme debate en torno a la «Tercera Vía» y han surgido opiniones muy críticas a su respecto. Por ejemplo, Alan Touraine la define como una sustitución de una política de protección por una política de iniciativas que suponga flexibilidad en la organización social, y el fomento de la capacidad de los individuos para tomar iniciativas ${ }^{78}$. Para Touraine esta concepción política responde al agotamiento del Estado de bienestar. La precariedad, que afecta entre un 20 y $25 \%$ de la población occidental, se alimenta tanto de las ayudas sociales propias del modelo francés, como del empleo a tiempo parcial y de duración determinada de modelo inglés y americano. La «Tercera Vía» combina objetivos económicos y sociales pero, siguiendo a Touraine, adopta como eje el liberalismo que intenta corregir, por medio de políticas sociales. Touraine sostiene que deben existir otras «terceras vías» ${ }^{79}$ y propone una vía «dos y medio» ${ }^{80}$.

${ }^{77}$ BLAIR, Tony, La Tercera Vía, El País/Aguilar, p. 80.

${ }^{78}$ TOURAINE, Alain, ¿Cómo salir del neoliberalismo?, Paidós, Barcelona, 1999, pp. 96-97.

${ }^{79}$ En la misma línea argumental, aunque desde una perspectiva más política, se sitúa el gran damnificado de la «Tercera Vía» alemana, el ex ministro de finanzas de Schröeder, Oskar Lafontaine en su libro El corazón late a la izquierda, Paidós, Barcelona, 1999. Otros autores, como Luis de Sebastián sostienen que habría que repensar el socialismo, ver: SEBASTIÁN, Luis de, «Repensar la segunda vía», El País, 6 de julio de 1999, p. 12 y SEBASTIÁN, Luis, El rey desnudo. Cuatro verdades sobre el mercado, Trotta, Madrid, 1999.

${ }^{80}$ En sus palabras, una vía «intermedia entre la antigua socialdemocracia y la «Tercera Vía», que tendría como prioridades la creación de empleo, el desarrollo sostenible y la comunicación intercultural TOURAINE, Alain, ¿Cómo salir del neoliberalismo?, Paidós, Barcelona, 1999, pp. 97. Hay una versión periodística de esta alternativa: TOURAINE, Alain, «3 y 21/2», El Pais, 31 de octubre de 1998, pp. 11-12. 
Para otros autores, como Ken Coates y Michael Barratt Brown, gran parte del discurso de la «Tercera Vía», está basado en los escritos del ex primer ministro conservador Harold MacMillan y en John Maynard Keynes, aunque estos pretendían básicamente ampliar la regulación del capitalismo, y Blair y Schroeder tratan de reducirla ${ }^{81}$.

Para Vicenç Navarro, la «Tercera Vía» incurrió en un defecto en su definición inicial, al posicionarse como alternativa entre el Partido laborista (que erróneamente se identificó con la socialdemocracia tradicional) y el neoliberalismo de Thatcher. El error de Guiddens era extrapolar la situación británica al resto de la socialdemocracia en Europa, donde ya se habían experimentado muchas de las cuestiones que el proponía. Guiddens aceptó esas críticas y en su libro Third Way and its critics $^{82}$, refiriéndose a Navarro, redefinió la «Tercera Vía» no como «una alternativa entre la socialdemocracia y el neoliberalismo, sino como la respuesta de la socialdemocracia a la globalización económica y revolución tecnológica, incluyendo como Tercera Vía desde las políticas desde las políticas desreguladores del mercado de trabajo del Gobierno neolaborista a la reducción de la semana laboral a 35 horas del Gobierno socialista francés ${ }^{83}$.

Navarro señala que la «Tercera Vía» británica pese a que tiene componentes de la socialdemocracia tradicional (énfasis en políticas activas) se distancia de ella acercándose más a las tradiciones cristianodemócratas (sobrecargar la familia) y liberales (desregulación del mercado de trabajo) ${ }^{84}$. Navarro deja claro que la «Tercera Vía» es un proyecto político de grupos profesiones y técnicos lo que explica su popularidad en los medios de información y centros financieros.

El politólogo Wolfgang Merkel encuentra tres cuestiones que no ha resuelto la «Tercera Vía». 1- El problema de los «pobres que trabajan». El Reino Unido ha visto como su número ha aumentado hasta ser dos veces más alto que en Alemania; 2- La concesión de demasiado poder en asuntos internos al Primer Ministro, con lo que sería imposible su aplicación en Italia, Alemania o España; 3- Falta de interés en adoptar el marco de la Unión Europeo como espacio estratégico para las políticas socialdemócratas. No hay planes para coordinar las políticas fiscales,

\footnotetext{
${ }^{81}$ Ken Coates y Michael Barratt Brown, «La Tercera Vía hacia el estado servil», JACQUES, Martin (ed.) ¿Tercera Vía o neoliberalismo?, Icaria, Barcelona, 2000, pp. 108-109.

${ }^{82}$ GUIDDENS, Anthony, The third way and its critics, Polity Press, 2000.

${ }^{83}$ Ver NAVARRO, Vicenç, «Las vías de la socialdemocracia», El País, 21 de julio de 2000, pp. 15-16.

${ }^{84}$ Esto explicaría sus alianzas internacionales, por ejemplo con el presidente español José María Aznar. Ver: NAVARRO, Vicenç, «Las vías de la socialdemocracia», p. 16.
} 
monetarias y sociales para estimular el crecimiento económico, el empleo y la justicias social ${ }^{85}$.

De todas formas, Blair ha sucumbido en determinados errores que ponen en tela de juicio todo su programa, como fue en su momento la guerra de la OTAN en la antigua Yugoslavia ${ }^{86}$, así como cierta intransigencia en asunto internos (como el caso de la alcaldía de Londres), y el abandono por los jóvenes y vanguardias de arte que le habían apoyado ${ }^{87}$. Ha demostrado tener un gran instinto político y en la mitad de su mandato intentó modernizar su partido y girar más hacia la izquierda, intentando hablar más de objetivos sociales concretos, sobre todo la sanidad pública y la recuperación de la «igualdad», el concepto de «radicalismo» y una «agenda moral». En ese marco, su frase: «la guerra de clases ha terminado. Estamos ahora en una lucha por la igualdad, y ésta acaba de comenzar» ${ }^{88}$. Unos meses después, el 7 de junio de 1999 publicó con Schröder ${ }^{89}$ un manifiesto sobre la «Tercera Vía» ${ }^{90}$, donde constataba cuatro tesis, que han sido razonadas críticamente por Sami Naïr ${ }^{91}$ :

1- Apoyo mayoritario a las fuerzas del mercado. Esto significaría la renuncia del Estado a regular la competitividad en la batalla entre empresas. Las empresas más poderosas pueden aplastar a las más débiles y los mercados de trabajo deberán adaptarse (flexibilidad). Sólo se contrata cuando se necesita.

${ }^{85}$ MERKEL, Wolfgang, «Las terceras vías de la socialdemocracia en el 2000», El País, 20 de julio de 1999, p. 12.

${ }^{86}$ Sobre el bombardeo sobre la antigua Yugoslavia, Blair escribió un artículo justificativo: BLAIR, Tony, «Por qué la generación del 68 optó por ir a la guerra», El País, 15 de abril de 1999.

${ }^{87}$ A partir de un artículo de la revista británica New Musical Express donde hacía referencia a la imposición del toque de queda para adolescentes y el aumento de los costes en las universidades. Ver, El País, 19 de marzo de 1998, p. 7.

${ }^{88}$ El País, 29 de septiembre de 1999, p. 7; También El País, 30 de septiembre de 1999, p. 14; y El Mundo, 29 de Septiembre de 1999, p. 24.

${ }^{89}$ Aunque se intentó desmarcar posteriormente. Una prueba es que en el congreso del SPD de diciembre de 1999, sólo se citó la «Tercera Vía» en un sentido crítico y no invitaron a Blair sino a Lionel Jospin y al sueco Göran Persson. Este hecho coincidió con la intervención del canciller para salvar la empresa Holzmann (segunda constructora alemana) de la bancarrota y mucha gente del paro. Esto representa, a juicio de algunos analistas, un intento de recuperar el electorado clásico del SPD y un abandono de las tesis neoliberales del «Neue Mitte», la versión alemana de la «Tercera Vía». Ver El País, 5 de diciembre de 1999, p. 4

${ }^{90}$ El texto se puede consultar en Tony BLAIR y Gerhard SCHROEDER, «La Tercera Vía. Europa: the third way-Die Neue Mitte» en ¿Tercera Vía o neoliberalismo?, pp. 25-41.

${ }^{91}$ NAÏR, Sami, «El liberalismo de izquierda», El País, 17 de diciembre de 1999, p. 16. 
2- Precarización del trabajo. Ninguna seguridad para el trabajo, toda la seguridad para los detentadores de riqueza. La precariedad se convierte en el elemento estructural del sistema.

3- En el «centro del contrato social debe situarse la ideología individualista»" ${ }^{92}$ En otras palabras, hay que aceptar la lucha, el riesgo y que gane el mejor.

4- Cuestionamiento de la protección social. Lo social se ve reducido a una «red de seguridad».

Naïr concluye con una crítica muy común a la «Tercera Vía», que es que pretende acabar con la idea de igualdad. Para Naïr lo que persigue es la clásica idea de la desigualdad como una condición del desarrollo económico liberal. Ahondando en esta particularidad, el editor jefe de The Observer, Will Hutton, ha escrito que «el Nuevo Laborismo ha aceptado una jerarquía de valores muy conservadora: la libertad en primer lugar, la fraternidad en segundo lugar y, en un modesto tercer lugar, la igualdad. El lenguaje de la lucha contra la desigualdad ha desaparecido por completo del discurso público». Hutton achaca esta circunstancia a que el Nuevo Laborismo si quiere ganar las elecciones no se puede definir abiertamente por la igualdad, porque el electorado que se preocupa por esos temas disminuye $\mathrm{e}^{93} \mathrm{y}$ porque las fuerzas que provocan la desigualdad (globalización, cambios de mercado laboral), parecen incuestionables ${ }^{94}$. Sobre esto mismo, otros autores como es el caso de Fernando Vallespín señalan que los valores de libertad, igualdad y solidaridad deben de ser reajustadas a las nuevas circunstancias, haciendo una alabanza de la «Tercera Vía»"

\footnotetext{
${ }^{92}$ Ver NAÏR, Sami, «El liberalismo de izquierda», p. 16.

${ }_{93}$ El historiador Eric Hobsbawm ha señalado que los ideólogos del Nuevo Laborismo consideran que después de Thatcher las mayorías dependían de la obtención de votos de la clase media thatcherista. HOBSBAWM, Eric, «La muerte del neoliberalismo», en JACQUES, Martin (ed.), ¿Tercera Via o neoliberalismo?, p. 47.

${ }^{94}$ HUTTON, Will, «La desigualdad» en JACQUES, Martin (ed.), ¿Tercera Vía o neoliberalismo?, pp. 89. Hutton no se queda simplemente en la crítica y propone nueve puntos para en los que habría que incidir para hacerle frente a la desigualdad: a) La dirección corporativa, las absorciones de empresas y el sistema financiero; b) Regulación y empresa publica; c) El acceso a la educación; d) Las pensiones de vejez; e) El Estado de bienestar universal; f) Los préstamos públicos y la iniciativa de financiación privada; g) La tributación; h) Medios de comunicación, deporte y cultura; i) La dimensión internacional.

${ }^{95}$ En un artículo de defensa de la «Tercera Vía», ver: VALLESPÍN, Fernando, «Elogio del socialismo ligero», El País, 5 de marzo de 1999, p. 15. En la misma línea se puede leer el artículo de INNERARITY, Daniel, «La socialdemocracia liberal», El País, 1 de junio de 2000, pp. 13-14.
} 
Otro crítico, el sociólogo Stuart Hall define la «Tercera Vía» como una delicada estrategia para dar rodeos más que para tratar problemas. Esa inexactitud semántica se manifiesta en la proliferación de equívocos adverbios como "entre», «encima» y «más allá» y en su intención de abarcarlo todo. "Carece de enemigos, admite a todo el mundo. El discurso de la Tercera Vía transmite el mensaje de que ya no quedan conflictos de intereses irreconciliables. Por ello su perspectiva es de con una política sin adversarios. Eso implica que, por algún transcendente milagro, unir los intereses representados, por ejemplo, por la prohibición sobre los anuncios de tabaco y los de Fórmula 1, una política exterior ética y la venta de armas a Indonesia, la diversidad de los medios de comunicación y la concentración del poder global del imperio de Rupert Murdoch.... ${ }^{96}$.

El profesor Hall también se muestra crítico con las responsabilidades que le atribuye la «Tercera Vía» y las nulas que le otorga a los negocios y el mercado. En este sentido, considera que el Nuevo Laborismo concibe la globalización en «términos muy simplistas, como un fenómeno único, coherente, unidireccional, con los mismos rasgos y los mismo resultados inevitables en todos los ámbitos ${ }^{97}$, con capacidad de autoregulación y que no requiere ningún marco social, cultural, político o institucional determinado. Esto, explica para Hall, la pasividad del gobierno de Blair en asuntos de política internacional, como la crisis de Asia, Rusia, etc.

El politólogo y director de la editorial Polity Press, David Held, recuerda que el Nuevo Laborismo ha adoptado una concepción de la globalización que domina desde la época de Thatcher y Reagan, que es la ortodoxia neoliberal, que entiende la globalización desde una perspectiva hiperglobista, donde la principal fuerza procede de la internacionalización de los procesos económicos, y donde la competencia global es algo ineludible, dejando a los Estados una capacidad decreciente para regular sus economías. Esto implica que los Estados ya no tienen instrumentos políticos necesarios para someterse al cambio económico global ${ }^{98}$. Held estudia

${ }^{96}$ HALL, Stuart, «El gran espectáculo hacia ninguna parte», en JACQUES, Martin (ed.), ¿Tercera Vía o neoliberalismo?, pp. 66. Para Hall, una de las características que impregna el proyecto de Blair es anunciar grandes debates que luego no se producen. En lugar de exponer clara y abiertamente las alternativas, se emprenden intensas relaciones públicas, con circunloquios y foros políticos, para hablar directamente a los miembros seleccionados del Gran Público Británico, fuera del alcance de los denostados «expertos y críticos».

${ }^{97}$ HALL, Stuart, «El gran espectáculo hacia ninguna parte», en JACQUES, Martin (ed.) ¿Tercera Via o neoliberalismo?, p. 68.

${ }^{98}$ Held argumenta que el Nuevo Laborismo se ha excedido al permitir con demasiada frecuencia que las fuerzas del mercado internacional manejen a su antojo el poder estatal. HELD, David, «La globalización», en JACQUES, Martin (ed.) ¿Tercera Vía o neoliberalismo?, p. 146. 
la globalización como un fenómeno multicausal, con su dimensión política, legislativa, militar, transnacional, y propone cinco puntos para su desarrollo ${ }^{99}: 1$ Regulación de la volatilidad de los mercados financieros internacionales y su búsqueda especulativa de ganancias a corto plazo; 2- Nuevas formas de coordinación económica en las organizaciones como FMI, Banco Mundial, OECD, G7 o $\mathrm{OMC}$; 3- Para restablecer los mercados es necesario ampliar la legislación para contrarrestar su indeterminación y los costes ambientales y sociales que genera; 4Vinculación a medidas encaminadas a aliviar los casos más precarios de penurias económicas evitables (reducción de deuda en países en desarrollo, facilidades económicas en organizaciones transnacionales y creación de fondos de seguros crediticios) para fortalecer el capitalismo global; 5- Fomento de las formas democráticas y los procesos democráticos más allá de las fronteras territoriales.

\subsection{Francia}

Muy crítico con la «Tercera Vía» de Blair/Schróder se ha mostrado el primer ministro francés Lionel Jospin ${ }^{100}$, quien ha manifestado que si la «Tercera Vía» se encuentra entre el capitalismo y el comunismo, sólo es un nombre diferente para el socialismo británico. Y si implica una posición equidistante de la socialdemocracia y el neoliberalismo «ése no es mi camino» ${ }^{101}$. Jospin ha desarrollado un estilo político sin perder de vista la paulatina adaptación socialdemócrata a la globalización económica y a la Unión Europea, pero sin descuidar los linderos políticos dentro de los cuales se sitúa y la realidad estatista francesa. También ha intentado moderar las consecuencias del llamado pensamiento político y económico único ${ }^{102}$. Reforzando la argumentación de la diferenciación del «proyecto francés», hay que notar que en este caso han tenido una gran importancia los movimientos sociales. En palabras de Jospin: «Reconocemos la globalización. Pero no consideramos su manifestación inevitable. De aquí que tratemos de crear un sistema de regulación de la economía capitalista global. Opinamos que a través de la acción conjunta europea se pueden reglamentar algunas áreas clave, como las finanzas, el comer-

${ }^{99}$ HELD, David, «La globalización», en JACQUES, Martin (ed.) ¿Tercera Vía o neoliberalismo?, pp. 152-154

${ }^{100}$ Líder de la llamada izquierda plural francesa compuesta por socialistas, comunistas, verdes y nacionalistas de izquierda, el llamado «Movimiento de los Republicanos», que lograron su victoria tras las dos vueltas de las elecciones francesas los días 25 de mayo y 1 de junio de 1997.

101 JOSPIN, Lionel, «La inútil tercera vía de Tony Blair», El País, 22 de noviembre de 1999, p. 17.

102 CAZORLA PRIETO, Luis María, «La encruzijada de Jospin», El País, 20 de octubre de 1999 , p. 16

Cuadernos de Estudios Gallegos, Tomo LI, Fascículo 117, Santiago 2004. (Págs. 375 - 403) 
cio o la informática», y añade, «no debemos rendirnos al concepto fatalista de que el modelo capitalista neoliberal sea el único disponible. Al contrario, debemos moldear el mundo según nuestros valores $\rangle^{103}$. Asimismo, Jospin sostiene que ser socialista significa tratar de reducir la desigualdad social, mantener el Estado de Bienestar, así como cuidar la educación, la cultura y la seguridad frente a la violencia y el crimen, y la igualdad frente a la vivienda, salud, información, ciudadanía y desigualdad entre sexos. Ha cumplido con su promesa estrella de la semana de 35 horas de trabajo y el programa de empleo juvenil, bajo la dirección de la «figura más popular de la izquierda en el gobierno» ${ }^{104}$, la ministra de Empleo y Solidaridad, Martine Aubry (hija de Jacques Delors).

Además de esos hechos puntuales, el columnista del International Herald Tribune, William Pfaff, descubre que «existe un método Jospin, consistente en consultas y discusiones constantes dentro del gobierno y una utilización considerable de estudios e informes hechos fuera de él por especialistas y personalidades universitarias ${ }^{105}$. El fin de esta propuesta es introducir a la comunidad intelectual y políticas en las decisiones socialistas y hacer uso de su autoridad para conseguir el apoyo popular y movilizar la opinión de abajo hacia arriba y no instruirla, como hacía el gobierno anterior. Al introducir una gran variedad de opiniones en el debate, cuando se toman las decisiones, permite a todas las partes sentir que se les ha escuchado. Ésta es una nueva práctica en Francia, acostumbrada a un autoritarismo jacobino ${ }^{106}$.

Otras «Terceras Vías» las han sostenido, por ejemplo, el ex ministro alemán Oskar Lafontaine y su esposa Christa Müller ${ }^{107}$. El libro de ambos ha sido editado en España con una acertada introdución de Juan Francisco Marín Seco ${ }^{108}$. En el libro, los autores intentan integrar todo lo bueno que ofrece la globalización con el

${ }^{103}$ JOSPIN, Lionel, «La inútil tercera vía de Tony Blair», El País, 22 de noviembre de 1999, p. 17.

${ }^{104}$ Ver PFAFF, William, «La nueva izquierda europea: el ejemplo francés», Política Exterior, n67, Enero/ Febrero 1999, pp. 66.

${ }^{105}$ PFAFF, William, «La nueva izquierda europea: el ejemplo francés», p. 67.

${ }^{106}$ Este método se ha empleado en la reforma de la política sobre inmigración y nacionalidad, programas sociales y pensiones, cargas sociales sobre asalariados y empresas, ley de familia, reforma escolar y universitaria, legislación sobre nuevas tecnologías y otros diversos asuntos. Ver PFAFF, William, «La nueva izquierda europea: el ejemplo francés», p. 67-68.

${ }^{107}$ Oskar Lafontaine y Christa Müller, No hay que tener miedo a la globalización. Bienestar y trabajo para todos, Biblioteca Nueva, Madrid, 1998. La defensa de muchas de esas ideas le sirvieron para tener que renunciar al ministerio de economía. Para el detalle, ver BIRNBAUM, Norman, «La derrota de Lafontaine y el futuro de Europa», El País, 17 de marzo de 1999, p.13.

${ }^{108}$ Quien ha tratado el tema en su libro MARTÍN SECO, Juan Francisco, La farsa neoliberal: refutación de lo liberales que se creen libertarios, Temas de Hoy, Madrid, 1995. 
sostenimiento del Estado de Bienestar y los derechos de los ciudadanos. El ensayo se refiere específicamente a Alemania, pero se puede aplicar a todos los países, debido a la similitud de las políticas en los diferentes países europeos. Otros autores, como el citado más arriba, Wolfgang Merkel $^{109}$ opina que la socialdemocracia será cada vez menos el partido de la clase obrera tradicional, anque eso no significa la renuncia a una sociedad más justa. «En las sociedades industriales desarrolladas en las últimas décadas, la desigualdad social ya estaba cada vez menos vinculada a la dicotomía clase obrera contra el resto de la sociedad. No obstante -añadealgunos de los viejos problemas, como los ciclos económicos, el paro y la desigualdad social, siguen existiendo y se reproducen constantemente. Todas estas líneas de fractura delimitan intereses diferentes, conflictos y necesidades de regulación en el capitalismo corregido por el Estado social del futuro, garantizando la supervivencia de la socialdemocracia ${ }^{110}$, explica Merkel.

John Roemer ${ }^{111}$ significa que el socialismo después de la caída del sistema comunista en la Unión Soviética y en la Europa del Este, sigue siendo un ideal que vale la pena perseguir. Pero cree, al contrario de los ideólogos y adalides de la «Tercera Vía», en un socialismo como forma de igualitarismo y no como la realización de una determinada relación de propiedad. También defiende que el capitalismo moderno proporciona varias experiencias fértiles para diseñar la nueva ola de experimentos socialistas, sobre todo en la relación entre el papel de la propiedad privada y de los mercados. Por último, hay otras «Terceras Vías» como la que ha propuesto de manera de boceto para latinoamérica Ricardo Lagos, muy en la línea Blair ${ }^{112}$.

\section{CONCLUSIÓN}

Más allá de enunciar algunas de las alternativas que han surgido durante los años 90 a la izquierda tradicional, lo cierto es que los socialdemócratas ganan en

${ }^{109}$ MERKEL, Wolfgang, ¿Final de la socialdemocracia? Recursos de poder y política de gobierno de los partidos socialdemócratas en Europa Occidental, Edicions Alfons el Magnànim, Valencia, 1995.

${ }^{110}$ MERKEL, Wolfgang, ¿Final de la socialdemocracia? Recursos de poder y politica de gobierno de los partidos socialdemócratas en Europa Occidental, pp. 360-361.

${ }^{111}$ En ROEMER, John E., Un futuro para el socialismo, Crítica, Barcelona, 1995.

112 Ver LAGOS, Ricardo, "Hacia una Tercera Vía latinoamericana», El País, 19 de julio de 1999, p. 11. Para una mayor información sobre la «Tercera Vía» en América Latina, ver: MODONESI, Massimo, «La tercera Vía en América Latina y el Consenso de Buenos Aires», Rebelion.org, 12 de diciembre de 2000.

Cuadernos de Estudios Gallegos, Tomo LI, Fascículo 117, Santiago 2004. (Págs. 375 - 403) 
estos momentos la partida ${ }^{113}$ : gobiernan 10 de los 15 países comunitarios. España, Austria y el Gran Ducado de Luxemburgo son las excepciones. En los dos restantes, Bélgica e Irlanda, la batuta la llevan los liberales. Aunque la amplia dominación socialdemócrata comienza a resquebrajarse. En Italia el populismo derechista de Berlusconi ya ha triunfado, en Alemania los democristianos le siguen de cerca al SPD. Ninguno de los gobiernos socialdemócratas coincide con los viejos esquemas de la izquierda europea. Todos ofrecen una perspectiva más pragmática que ideológica. La política de la izquierda se orienta hoy más a la resolución de problemas $^{114}$, aunque esos problemas, como se ha explicado, se resuelven de una forma diferente. Ha quedado claro que hay diferentes «Terceras Vías», que ninguna es la "Tercera Vía», «no hay una sola tercera vía en la socialdemocracia, sino tantas como situaciones de las que se parte», señala acertadamente Joaquín Estefanía ${ }^{115}$. Esto es lo que ha venido sucediendo en los últimos años y lo que se ha tratado de explicar aquí. El socialismo europeo se ha polarizado en dos ejes, el socialismo más tradicional de Jospin y la «Tercera Vía» de Blair. Pese a los intentos de síntesis y unidad, como el de el Congreso Mundial de la Organización de la Internacional Socialista celebrado en París en el año 99, se ha comprobado que no existe una visión única sobre la resolución de problemas ${ }^{116}$. Pese a las discrepancias, de ese Congreso salió el proyecto de Progreso Global establecido en la «Declaración de París» ${ }^{117}$ el 8 de noviembre de 1999, donde reclamaron genéricamente la "supremacía de la política sobre el mercado» ${ }^{118}$. Unos días después, en el seminario «El

\footnotetext{
${ }^{113}$ Pese a que, como se señaló al principio, el momento álgido fue el año 98 cuando eran 12 los gobiernos socialistas en Europa. El sentimiento de euforia en determinados círculos era muy palpable. Un claro ejemplo era el presidente de la Internacional Socialista y ex-primer ministro de francia Pierre Mauroy. Veáse: MAUROY, Pierre, «Europa: el futuro socialista», El Mundo, 4 de abril de 1999, p. 4-5.

${ }^{114}$ PFAFF, William, «La nueva izquierda europea: el ejemplo francés», pp. 60-61.

${ }^{115}$ ESTEFANÍA, Joaquín, «Distintas terceras vías», El País, 27 de junio de 1999, p. 60.

${ }^{116}$ Incluso su presidente, Pierre Mouroy, alentó a que «nuestra internacional debe seguir siendo socialista» y propuso «llevar la contraria al texto de Blair y Schoröder». Ver El País, 7 de noviembre de 1999 , p. 8.

${ }^{117}$ La Declaración de París comprometió a lo socialistas en seis puntos: 1- Lucha contra la pobreza y el hambre, contra la explotación y la desigualdad de acceso a los recursos económicos y tecnológicos mundiales; 2- Lucha por los derechos humanos y la democracia; 3- La construcción de la paz y la seguridad; 4- Reforma de la ONU y ampliación del número de miembros del Consejo de Seguridad. Reforma del FMI, el BM y la OMC; 5- Dar respuestas al problema del ecosistema; y 6- Europa anticipa un modelo de regionalismo abierto y adecuado. Ver El País, 9 de noviembre de 1999.

${ }^{118}$ Ver: El País, 9 de noviembre de 1999, p. 6; El Mundo, 9 de noviembre de 1999.
} 
Reformismo en el siglo XXI», se volvieron a ver las diferencias entre las familias. Así mientras Jospin abogaba por un Estado nacional, Clinton y Blair defendían una visión globalista ${ }^{119}$.

Se puede afirmar que dentro de las diferentes «Terceras Vías» que encarnan los desafíos de la nueva socialdemocracia, hay tres que sobresalen del resto. Por un lado, la tendencia socialista de francés Lionel Jospin, por otro la tendencia socialliberal del alemán Gerhard Schröder, y por último tendencia liberal de Tony Blair. Aunque como bien señala el premio Nobel de Economía Gary S. Becker la política ha quedado aplastada por el interés propio de cada gobierno. Así Schroeder ha reducido el impuesto sobre sociedades fomentando la creación de empresas y ha prometido exenciones fiscales para los planes de pensión privados. Por su parte, Jospin ha liberalizado discretamente el mercado laboral francés impulsando los empleos a tiempo parcial y las privatizaciones, y fomentando un sistema financiero mundial más competitivo y con menos control estatal. Cabe preguntarse pues, como apunta Becker, si la «Tercera vía» es en realidad una vía de derechas ${ }^{120}$.

Para los primeros de este nuevo siglo se anuncia otro cambio, al constatarse la pérdida de la presidencia de los Estados Unidos por parte de los demócratas conducidos por Al Gore en favor de George W. Bush Jr, el hijo del ex-presidente Bush, que ha reformulado la «New Right» denominándola «conservadurismo compasivo» ${ }^{121}$. Por su parte Blair ha triunfado recientemente en las elecciones del año 2001 con una propuesta más pragmática y europeista, donde ha desaparecido ya el término «Tercera Vía» (por el de «socialdemocracia renovada») por su propia crisis, sobre todo después de la guerra de la OTAN en Kosovo ${ }^{122}$. Además esto ha venido apuntillado por los cambios que han surgido tras los acontecimientos de Chiapas y manifestaciones en Francia primero, y los movimientos antiglobalización a partir del año 1999 en Seattle, demostrando que aumenta la posibilidad que la globalización neoliberal haya sembrado la semilla de su propia destrucción, dando margen para que surja una nueva izquierda alternativa alrededor de estos grupos antiglobalización, los cuales han planteado sus propias propuestas para una

${ }^{119}$ El País, 22 de noviembre de 1999, p. 2.

${ }^{120}$ BECKER, Gary S., «La tercera vía es una vía de derechas», El País, 27 de agosto de 2000 , p. 12

${ }^{121}$ Los primeros pasos de Bush Jr. han sido los nombramientos de sus colaboradores más cercanos. Los conservadores Thomas Thompson (salud) y John Ashcroft (justicia) serán la más clara definición del conservadurismo ideológico de la nueva Administración. Por otro lado, ha aprobado una serie de ayudas y subvenciones a las diferentes congregaciones religiosas estadounidenses.

${ }^{122}$ Ver El País, 27 de mayo 2001, p. 6.; y COLOMER, Josep M., «La segunda tercera vía», El País, 17 de abril de 2001, p. 11. 
globalización diferente, como ha sucedido en el Foro Social Mundial de Porto Alegre. Con esto se puede afirmar que pese al enorme apoyo mediático de la «Tercera Vía» de Blair, ha resultado victoriosa la «Tercera Vía» de Jospin, quien ha convertido su propuesta en la auténtica alternativa socialdemócrata. Además de sus éxitos sociales, ha llevado los indicadores macroeconómicos a unos índices impensables, contra toda previsión, y Francia puede alardear de un futuro económico prometedor. Además, al igual que el «Olivo» italiano, se han comprometido con los movimientos antiglobalización.

De todas formas, las nuevas alternativas empiezan a venir de la izquierda alternativa. Por un lado hay que reseñar los importantes resultados electorales para esa izquierda en Francia, Holanda ${ }^{123}$, Dinamarca e incluso España e Italia, y por otro lado la nueva izquierda que ha surgido dentro de los grupos antiglobalización. Con lo cual se puede afirmar que la «Tercera Vía» como alternativa al neoliberalismo, si es que alguna vez lo intentó ser, ha fracasado, al mostrarse sólo como una continuación de las políticas ultraliberales de los años 80 (salvo, como se ha explicado, el caso de Francia).

${ }^{123}$ Ver Viento Sur, no 38, junio 1998, pp. 33-34. 